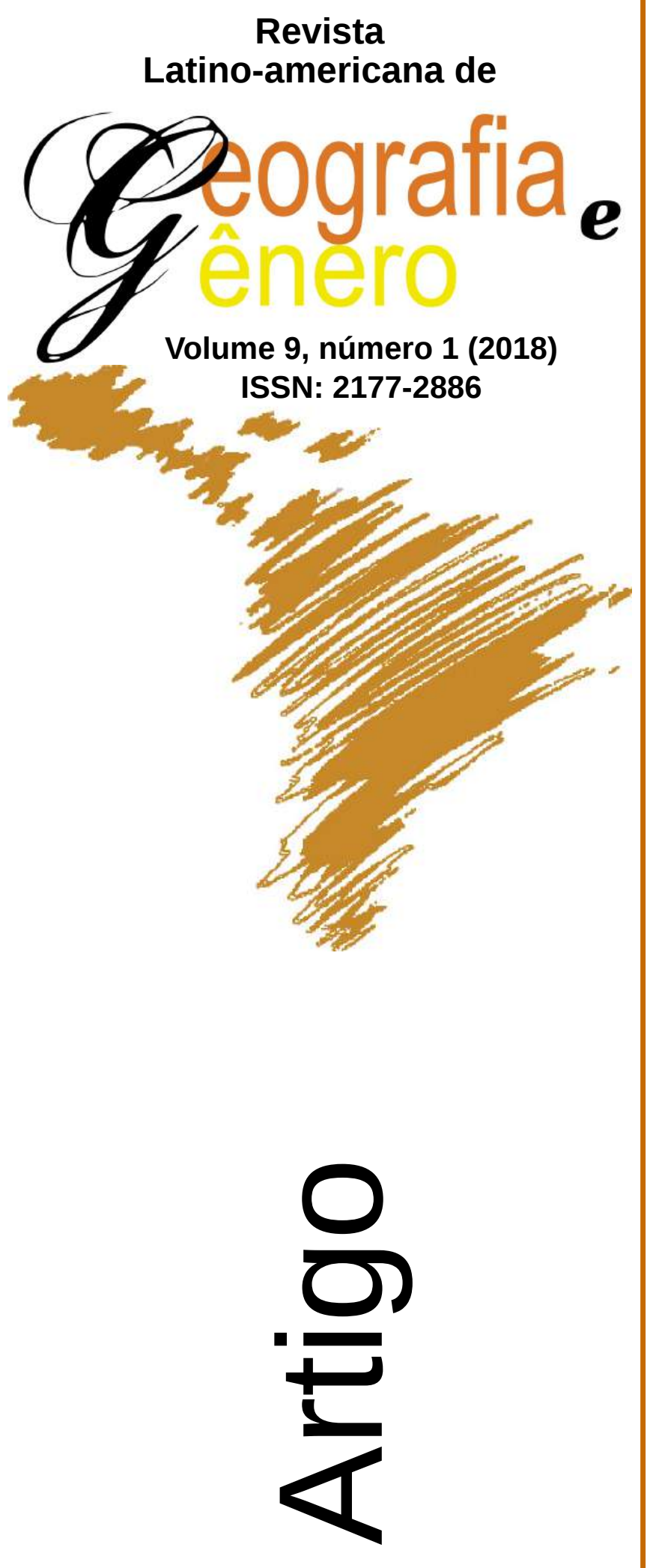

\title{
Talento Criativo em Mulheres Brasileiras
}

Talento Creativo en Mujeres Brasileñas

Creative Talent in Brazilian Women

Maria Célia Bruno Mundim

Pontifícia Universidade Católica, Campinas Brasil

celiamundim@gmail.com

Marco Antônio dos Santos

Pontifícia Universidade Católica, Campinas Brasil

mrs38@uol.com.br

Chaielen Marchiolli Barboza Martinez

Pontifícia Universidade Católica, Campinas -

Brasil

chaielenmbm@hotmail.com

Silvana Maria Nader

Pontifícia Universidade Católica, Campinas Brasil

silvana@mncom.com.br

Solange Muglia Wechsler

Pontifícia Universidade Católica, Campinas Brasil

wechsler@lexxa.com.br

Como citar este artigo:

MUNDIM, Maria Célia Bruno; SANTOS, Marco Antônio; MARTINEZ, Chaielen Marchiolli Barboza; NADER, Silvana Maria; WECHSLER, Solange Muglia. Talento Criativo em Mulheres Brasileiras. Revista Latino Americana de Geografia e Gênero, v. 9, n. 1, p. 138-156, 2018. ISSN 2177-2886.

Disponível em:

http://www.revistas2.uepg.br/index.php/rlagg 


\title{
Talento Criativo em Mulheres Brasileiras
}

\author{
Talento Creativo en Mujeres Brasileñas
}

\author{
Creative Talent in Brazilian Women
}

\begin{abstract}
Resumo
O objetivo deste estudo foi analisar os fatores psicológicos e ambientais que influem no talento criativo de mulheres brasileiras de diferentes áreas. A amostra foi composta por seis mulheres reconhecidas por talento criativo por meio de premiações. $\mathrm{O}$ instrumento utilizado foi o Roteiro de Entrevista formado por questões semiabertas relacionadas ao processo criativo e ao trajeto de vida. Por meio da análise de conteúdo foram verificadas as categorias de respostas das participantes mais presentes em suas falas, tais como fatores ambientais favoráveis à criatividade, mentores, motivação, barreiras, administração da vida pessoal e profissional, processo criativo, características pessoais cognitivas e de personalidade. Concluise sobre a significância de entender os aspectos psicológicos e as condições ambientais que favorecem o talento criativo em mulheres.
\end{abstract}

Palavras-Chave: Mulher; Gênero; Talento; Criatividade; Excelência.

\section{Resumen}

El objetivo de este estudio fue analizar los factores psicológicos y ambientales que influyen en el talento creativo de mujeres brasileñas de diferentes áreas. La muestra se compuso de seis mujeres reconocidas por su talento creativo a través de premios. El instrumento utilizado fue el guión de la entrevista formado por preguntas semiabiertas relacionadas con el proceso creativo y la trayectoria de vida. A través del análisis de contenido se verificaron las categorías de respuestas de las participantes más presentes en sus discursos, tales como factores ambientales favorables a la creatividad, mentores, motivación, barreras, gestión de la vida personal y profesional, proceso creativo, características personales cognitivas y de personalidad. Se concluye apuntando a la importancia de entender los aspectos psicológicos y las condiciones ambientales que favorecen el talento creativo en las mujeres.

Palabras-Clave: Mujer; Género; Talento; Creatividad; Excelencia.

\begin{abstract}
The purpose of this study was to analyze the psychological and environmental factors that influence Brazilian women's creative talent in different fields. The sample was composed of six women whose creative talent was recognized by awards. The instrument was an Interview Guide composed by semi-open questions related both to creative process and life trajectory. A content analysis of the participants' responses indicates that some categories are frequently present in their speech: environmental factors favorable to creativity; mentoring; motivation; barriers; personal and professional life management; creative process; personal and cognitive characteristics. In conclusion, it points out that it is important to understand the psychological aspects and the environmental conditions that favor women's creative talent.
\end{abstract}

Keywords: Woman; Gender; Talent; Creativity; Excellence.

Maria Célia Bruno Mundim, Marco Antônio dos Santos, Chaielen Marchiolli Barboza Martinez, Silvana Maria Nader, Solange Muglia Wechsle 


\section{Introdução}

Ao longo da história ocidental sempre existiram mulheres que se rebelaram contra sua condição de vida e que lutaram por mais direitos e liberdade. $\mathrm{Na}$ década de 1960 o feminismo ganhou força inspirado por Simone de Beauvoir, que já em 1949 em seu livro 'O Segundo Sexo', afirmava que não se nascia mulher, mas tornava-se mulher (PINTO, 2010). Sua proposta era indagar sobre as relações entre sexo biológico e a construção da categoria social da mulher (MACHADO, 1998). Se inicialmente o movimento feminista esteve articulado com outros movimentos sociais e causas específicas (CORRÊA, 2001), hoje, as causas que uniram gerações de mulheres estão emergindo dos blogs, coletivos e redes sociais. Porém um dos pontos centrais do feminismo é sob a ótica econômica, pela participação da mulher no mercado de trabalho. Mesmo com o aumento da participação das mulheres no mercado de trabalho e da diminuição da diferença salarial média entre os dois gêneros, masculino e feminino, as mulheres ainda enfrentam uma grande dificuldade de serem remuneradas e promovidas em relação aos homens (MADALOZZO, MARTINS \& SHIRATORI, 2010).

No Brasil, o crescimento da participação feminina no mercado de trabalho é resultante de diferentes fatores, dentre eles o significativo crescimento do nível de escolaridade das mulheres (INSTITUTO BRASILEIRO DE GEOGRAFIA E ESTATÍSTICA, 2011). Porém, o estereótipo de gênero e as consequências geradas por este estereótipo para a execução de papéis femininos impossibilitam que muitas mulheres alcancem a notoriedade com contribuições relevantes em diversas áreas, especialmente em campos de trabalho considerados como masculinos (ALENCAR \& VIRGOLIM, 2001).

Nas áreas de engenharias e tecnologias, por exemplo, a discriminação, a alta competitividade e a associação com a virilidade masculina fazem com que a representação das mulheres ainda seja pouco expressiva (LOMBARDI, 2004). Em outras áreas como a publicidade, os departamentos de criação e de gestão normalmente são monopolizados por homens (HACKLEY \& KOVER, 2007). Quanto às ciências, embora haja uma maior proporção entre os gêneros, as mulheres ainda competem desigualmente com os homens (NOGUEIRA, 2011), haja vista o domínio masculino no espaço público. Espaço este retratado enquanto reprodução das normas culturais de gênero, ou seja, das distintas espacialidades produzidas por meio das práticas sociais (OBERHAUSER et al, 2003). Como refere Campos et al (2018) várias questões relacionadas ao gênero e poder persistem ao longo da história, não permitindo mudanças de ordem prática.

Já nas organizações, apesar do predomínio masculino, a liderança feminina tem sido um tema contínuo na literatura internacional (LADEGAARD, 2011; PEUS, BRAUN \& KNIPFER, 2015; TOH \& LEONARDELLI, 2012). Contudo, há carência de estudos acerca do talento criativo feminino nas demais áreas, tornando o tema pertinente.

Por talento entende-se a aptidão ou o desempenho para uma área, resultando em uma potencialidade para fazer algo (GUENTHER \& RONDINI, 2012). Desse modo, os talentos são variados e, dentre eles, destaca-se o criativo. 
Assim sendo, a pessoa talentosa criativa é reconhecida por suas ideias e produtos sincronicamente úteis e originais em um determinado momento sócio-histórico (RUNCO, 2007; RUNCO \& JAEGER, 2012).

Quanto ao talento criativo feminino, este é determinado por diferentes fatores, como por exemplo, o ambiente familiar (WALTON \& KEMMELMEIER, 2012; WECHSLER, 2008). Os pais têm papel importante na identificação do talento, no apoio da aprendizagem, no incentivo para o aumento da capacidade cognitiva e de socialização, bem como no envolvimento afetivo e na transmissão de valores culturais (DELOU, 2007; REICHENBERG \& LANDAU, 2009; SHAVININA, 2013). Assim sendo, o estímulo dos pais para a autoafirmação, independência e curiosidade da criança colaboram para o seu desenvolvimento criativo (ALENCAR \& FLEITH, 2003). Embora para Piirto (2004) e Runco (2006) a criança potencialmente criativa já apresente indicadores comportamentais, como por exemplo, a independência de pensamento, a autonomia, o comportamento original e espontâneo. Além disso, a associação de traços de temperamento de extroversão e intuição ao desempenho criativo de pré-adolescentes e adolescentes é sugerido no estudo de Nakano e Castro (2013).

A mentoria também tem papel importante para a realização criativa, pois propicia aprendizagem e desenvolvimento profissional do indivíduo (KEINÄNEN \& GARDNER, 2006; TORRANCE, 1983). Nolna, Mekongo e Leke (2017), por exemplo, observaram o desenvolvimento de mulheres líderes em pesquisa na área da saúde por meio de mentoria. Além disso, Whitten (2017) notaram que estratégias de apoio como a orientação aumentam o nível de trabalho das mulheres no meio acadêmico.

Similarmente, a escola e o auxílio dos professores são fundamentais para o progresso intelectual e acadêmico das estudantes (SILVA, FERREIRA \& FERREIRA, 2014). Cabe ao professor o papel fundamental na descoberta e estímulo tanto do pensamento quanto do comportamento criativo (WECHSLER \& SOUZA, 2011). Em determinadas habilidades, como matemática e ciências, a menina tem maior interesse e melhor desempenho quando é encorajada a expandir em tais tipos de raciocínio (HILL, CORBETT \& ST. ROSE, 2010). Tal suporte é importante, pois geralmente as meninas apresentam menos autoconfiança do que os meninos em sua habilidade para solucionar problemas de ciências ou de matemática, além de serem mais predispostas a manifestar intensos sentimentos de ansiedade em relação à matemática, mesmo dentre aquelas com desempenho elevado (OECD, 2015). Por outro lado, a mulher experimenta discriminação quando opta por áreas acadêmicas predominantemente masculinas de acordo com Alencar e Fleith (2008). Além disso, os estereótipos femininos geram expectativas e preconceitos à mulher no local de trabalho (ENGEN, LEEDEN \& WILLEMSEN, 2001).

A distinção sofrida pela mulher em campos profissionais específicos acaba por fazer com que ela prefira diversificar seus esforços criativos, em vez de expor devoção ao seu trabalho (REIS, 2002a). Deste modo, ela tende a apresentar um nível baixo de autoestima em relação às suas aptidões, menosprezando suas habilidades (GARCÍA COLMENARES, 1997). Por conseguinte, as mulheres tendem a aparecer em menor número em estudos 
sobre pessoas talentosas (LANDAU, 2002), bem como falta reconhecimento de suas contribuições ao longo da história (REIS, 2005).

Outro aspecto que interfere no estímulo ou na inibição da criatividade é o contexto cultural que repercute no julgamento e nos níveis da manifestação criativa em cada área (LUBART, 2007). Logo, o fenômeno da criatividade pessoal pode ser explicado por meio das interferências da própria cultura sob o indivíduo, o que diferencia a expressão criativa entre diferentes culturas (CSIKSZENTMIHALYI, 2005). Nesta perspectiva, Morais (2001) explica que a proporção de produção criativa do gênero feminino parece ser definida por um conjunto de fatores sociais, dentre eles as circunstâncias de trabalho desiguais entre homens e mulheres.

As mulheres continuam sendo impactadas de maneira distinta no que refere à remuneração e à precariedade das condições no mercado de trabalho (KREIN \& CASTRO, 2017). Prado e Fleith (2012), por exemplo, verificaram que pesquisadoras de destaque de diferentes áreas enfrentavam dificuldades para conciliar a vida profissional com a pessoal, o estereótipo de gênero ao longo da carreira, além das condições e estrutura do trabalho desfavoráveis. Alencar e Fleith (2008), também constataram a repressão social como tipo de bloqueio à expressão criativa mais citada pelas estudantes de engenharia.

Ainda no que diz respeito às barreiras do potencial criativo, há os fatores internos tais como conferir o sucesso à sorte do que ao talento inerente, temor do sucesso, desconfiança e negação sobre as próprias habilidades e talentos, impasse em decisões e perfeccionismo (PEARCE, 2013; REIS, 2002a, 2002b). De modo similar, Pérez e Freitas (2013) também observaram que as próprias mulheres talentosas são resistentes em perceber características criativas em si mesmas como, por exemplo, a curiosidade, a inventividade, a originalidade e o desagrado com a rotina.

O talento feminino, inclusive o criativo, acontece sempre que a personalidade, o ambiente, a habilidade e a percepção pessoal agem estimulando a produção desse talento (REIS, 2005). Portanto, o potencial criativo está relacionado à interação entre os processos cognitivos, as características de personalidade e elementos ambientais, numa sinergia entre aspectos educacionais, sociais e culturais (WECHSLER, 2008). Assim sendo, dentre as variáveis cognitivas associadas com as variáveis de personalidade, a criatividade tem papel de destaque para a excelência e para a realização profissional em áreas específicas (ALMEIDA \& WECHSLER, 2015). Em pesquisas de Mundim e Wechsler (2015), Mundim, Morais e Wechsler (2015) sobre a excelência criativa em mulheres, observou-se a influência de fatores familiares tais como o modelo do pai, além de características criativas cognitivas, tais como a originalidade e de características de personalidade liderança, intuição e motivação intrínseca.

Por sua vez, a motivação intrínseca refere-se à dedicação e ao contentamento do indivíduo por determinada atividade, independente de reforços ambientais, sendo este aspecto psicológico importante para a criatividade (AMABILE, 1996). A necessidade que o indivíduo demonstra em trabalhar pelo prazer proporcionado com o trabalho por um grande período de tempo, o que despende alta energia física e psíquica, denominado por estados de flow por Csikszentmihalyi (1997), é constantemente observado em pessoas 
criativas e possivelmente também utilizada em atividades físicas.

Estudos sobre pessoas com excelência criativa de ambos os gêneros têm conferido certas características afetivas e cognitivas comuns a elas (TORRANCE, 1995; WECHSLER, 2006). Deste modo, atributos tais como a flexibilidade, a fluência, a abertura ao novo, a atração pela complexidade, a predileção pela linguagem metafórica (GUILFORD, 1967; STARKO, 2010) estariam relacionados à produção criativa. Também as características psicológicas como, por exemplo, a autoconfiança, a persistência, a sensibilidade interna e externa/intuição, a preferência por situações de risco, a liderança, o sentido de destino criativo aparecem em ambos os gêneros, sugerindo o conceito de "androgenia psicológica", no sentido de que homens e mulheres criativos são mais semelhantes entre si do que quando comparados com a população do mesmo sexo (MARTINSEN, 2011; MORAIS, 2013; RUNCO \& PRITZKER, 2011; SIMONTON 2000; TORRANCE, GOFF \& SATTERFIELD, 1998; WECHSLER, 2008). Em estudo com pessoas talentosas criativas brasileiras, por exemplo, foram verificadas semelhanças entre mulheres e homens criativos em relação ao seu estilo de pensar assim como em suas características de personalidade (WECHSLER, VENDRAMINI \& OAKLAND, 2012).

A pessoa talentosa criativa sobressai-se pela singularidade de seu pensamento, por apresentar ideias divergentes, além de soluções diferentes e inovadoras, pela sensibilidade para com as questões ambientais e por ter ao mesmo tempo um sentimento de desafio diante da desordem dos fatos (GUENTHER, 2000). Assim sendo, a flexibilidade tem função importante para a pessoa criativa, pois possibilita a mesma estar aberta às novas ideias e à mudança (SMITH \& AMNER, 1997) sendo associada usualmente a outros aspectos cognitivos, como por exemplo, o inconformismo (AMABILE, 1996). Por sua vez, a originalidade definida como a habilidade para produzir ideias que se afastam do senso comum, envolve ir além do óbvio e do jeito comum de pensar na busca por soluções alternativas para os problemas (NAKANO, 2015) e refere-se ao aparecimento de ideias incomuns. Entretanto, é muitas vezes ressaltado que uma ideia original não ocorre ao acaso, mas também depende do conhecimento em áreas específicas (RIETZSCHEL, NIJSTAD \& STROEBE, 2007). Para o surgimento de ideias e descobertas originais durante o processo criativo, a incubação também tem papel relevante (SIO \& RUDOWICZ, 2007). Durante a incubação podem surgir maior quantidade de soluções ao problema, haver insight, despontar ideias novas e originais através da casualidade (serendipidade) ou de analogias (PATRICK, 1986).

Considerando a relevância da expressão criativa feminina para os vários setores sociais, este estudo objetivou analisar os aspectos psicológicos e ambientais que influem no talento de mulheres brasileiras reconhecidas por sua criatividade em diferentes áreas de atuação. Para isso, considerou-se informações fornecidas por mulheres de destaque com o intuito de analisar os fatores biográficos que influenciaram a expressão criativa.

\section{Metodologia}

Participantes

Maria Célia Bruno Mundim, Marco Antônio dos Santos, Chaielen Marchiolli Barboza Martinez, Silvana Maria Nader, Solange Muglia Wechsle 
Participaram deste estudo 6 mulheres brasileiras reconhecidas socialmente como talentosas criativas em diferentes áreas de atuação, residentes no Estado de São Paulo. A idade média destas mulheres foi de 48 anos, com desvio padrão de 6,79 , sendo que a idade mínima foi de 36 anos e a máxima de 55 anos. $\mathrm{O}$ critério de inclusão foi a produção profissional reconhecida por meio de, pelo menos uma premiação (a nível local, regional, nacional ou internacional) nas suas áreas de atuação - relações públicas $(\mathrm{N}=2)$, negócios $(\mathrm{N}=1)$, defensoria pública $(\mathrm{N}=1)$, jornalismo $(\mathrm{N}=1)$ e artes cênicas $(\mathrm{N}=1)$.

A média de sua atuação profissional foi de 25 anos, com desvio padrão de 3,25 . Já a média de produção criativa reconhecida foi de 2,83 , sendo o desvio padrão de 2,04. Quanto ao estado civil das participantes, a maioria era casada, uma divorciada e uma solteira. A quantidade de descendentes entre elas variou em dois filhos $(\mathrm{N}=2)$, um filho $(\mathrm{N}=2)$ e ausência de filhos $(\mathrm{N}=2)$.

\section{Instrumento}

Este Roteiro de Entrevista (WECHSLER, ROMO \& MORAIS, 2013), é baseado na literatura sobre as características de mulheres criativas. É composto por quinze questões semiabertas relacionadas à infância, adolescência, carreira, processo e evolução do trabalho, características pessoais cognitivas e de personalidade, obstáculos/bloqueios pessoais, mentoria, administração da vida pessoal e profissional e desafios na atualidade.

\section{Procedimento}

As informações a respeito de mulheres com destaque e premiações em suas áreas de atuação foram obtidas através de contatos pessoais e indicações. Após identificar essas mulheres, os pesquisadores contataram as mesmas para entrevistá-las. Elas assinaram o Termo de Consentimento Livre e Esclarecido (TCLE) aceitando participar, espontaneamente, do estudo. As entrevistas foram realizadas individualmente em seus locais de trabalho e com média de uma hora de duração.

As respostas obtidas com o Roteiro de Entrevista foram consideradas através da análise de conteúdo segundo Bardin (2011). Assim sendo, as respostas foram categorizadas pela frequência de incidência de itens. Posteriormente, foram agrupados os temas encontrados em categorias mais amplas. Estas categorias foram dispostas para verificar as categorias de respostas entre as participantes.

\section{Resultados}

A seguir são apresentadas na Tabela 1, Tabela 2 e Tabela 3 as categorias e subcategorias da análise do conteúdo das respostas. São elencados também alguns exemplos de respostas equivalentes a estas categorias das mulheres talentosas. 
Talento Criativo em Mulheres Brasileiras

Tabela 1. Frequência de respostas das participantes nas categorias e subcategorias da análise de conteúdos relacionados à infância, adolescência e interesse profissional.

\begin{tabular}{|c|c|c|}
\hline TEMÁTICA & \begin{tabular}{|l} 
FREQUÊNCIA \\
DE \\
RESPOSTAS
\end{tabular} & EXEMPLOS DE RESPOSTAS \\
\hline \multicolumn{3}{|c|}{ Brincadeiras na infância } \\
\hline - Com bonecas & 3 & $\begin{array}{l}\text { "Quando criança eu adorava brincar de } \\
\text { casinha, pentear e fazer roupas para } \\
\text { minhas bonecas.” (empresária) }\end{array}$ \\
\hline - Brincadeiras de rua & 3 & $\begin{array}{c}\text { "Brincadeiras de rua - taco..." } \\
\text { (jornalista) }\end{array}$ \\
\hline \multicolumn{3}{|c|}{ Comportamento na adolescência } \\
\hline - Tímida & 1 & $\begin{array}{l}\text { "Tímida, muitoooooo tímida..." } \\
\text { (empresária) }\end{array}$ \\
\hline - Rebelde & 2 & $\begin{array}{l}\text { "Eu fui uma adolescente muito } \\
\text { revoltada..." (relações públicas A) }\end{array}$ \\
\hline \multicolumn{3}{|c|}{ Interesse pela área de atuação } \\
\hline - Na adolescência & 5 & $\begin{array}{l}\text { "Olha, foi uma coisa muito por acaso. } \\
\text { Estava no colegial e precisava definir } \\
\text { uma profissão... Lendo uma revista } \\
\text { científica vi a descrição de Relações } \\
\text { Públicas e falei "é isso que eu quero } \\
\text { fazer”". (relações públicas B) }\end{array}$ \\
\hline \multicolumn{3}{|c|}{ Mentores } \\
\hline - Pai & 1 & $\begin{array}{l}\text { "Tem horas que eu procuro frases, } \\
\text { situações, comportamento dele (pai) e } \\
\text { tem horas que eu tento realmente } \\
\text { copiar. Eu acho que tem sim uma } \\
\text { influência forte." (relações públicas A) }\end{array}$ \\
\hline - Chefe & 1 & $\begin{array}{l}\text { "...eu tive um chefe na minha história } \\
\text { que foi muito marcante para eu } \\
\text { continuar acreditando na profissão..." } \\
\text { (relações públicas B) }\end{array}$ \\
\hline - Professor & 1 & $\begin{array}{l}\text { "...eu queria essa pessoa (professor de } \\
\text { teatro) que me guiasse..." (atriz) }\end{array}$ \\
\hline
\end{tabular}

Maria Célia Bruno Mundim, Marco Antônio dos Santos, Chaielen Marchiolli Barboza Martinez, Silvana Maria Nader, Solange Muglia Wechsle 
Talento Criativo em Mulheres Brasileiras

Tabela 2. Frequência de respostas das participantes nas categorias e subcategorias da análise de conteúdos relacionados às características pessoais e criatividade.

\begin{tabular}{|c|c|c|}
\hline \multicolumn{3}{|c|}{ Características pessoais cognitivas } \\
\hline - Flexibilidade & 3 & $\begin{array}{c}\text { "Quando eu não sei sair do problema o } \\
\text { que eu faço é contar a mesma história } \\
15 \text { vezes, pra eu ouvir o problema, pra } \\
\text { ver se acabo vendo de outra forma." } \\
\text { (relações públicas B) }\end{array}$ \\
\hline \multicolumn{3}{|c|}{ Características pessoais de personalidade } \\
\hline - Abertura ao novo & 5 & "Vc tem que ir pro mundo..." (atriz) \\
\hline - Persistência & 6 & "Acho que teimosia." (empresária) \\
\hline $\begin{array}{l}\text { - Atração pela } \\
\text { complexidade }\end{array}$ & 1 & $\begin{array}{c}\text { "Eu preciso estar fazendo muitas coisas } \\
\text { ao mesmo tempo..." (relações } \\
\text { públicas B) }\end{array}$ \\
\hline - Inconformismo & 1 & $\begin{array}{l}\text { "O incômodo me tira do lugar e me faz } \\
\text { criar alguma coisa que me faça } \\
\text { contribuir e terminar com aquele } \\
\text { incômodo." (relações públicas A) }\end{array}$ \\
\hline \multicolumn{3}{|c|}{ Motivação } \\
\hline $\begin{array}{l}\text { - Intrínseca/Missão } \\
\text { criativa }\end{array}$ & 6 & $\begin{array}{l}\text { "Vejo mais ainda como obrigação de } \\
\text { que isso (teatro) tem que levar pro } \\
\text { mundo!" (atriz) }\end{array}$ \\
\hline \multicolumn{3}{|c|}{ Processo criativo } \\
\hline $\begin{array}{l}\text { - Condições } \\
\text { ambientais }\end{array}$ & 3 & $\begin{array}{l}\text { "O café do domingo e o jornal, eu curto } \\
\text { isso, muito..." (relações públicas A) }\end{array}$ \\
\hline $\begin{array}{l}\text { - Processo de } \\
\text { incubação }\end{array}$ & 3 & $\begin{array}{l}\text { “...muitas vezes as ideias se desdobram } \\
\text { em algo que só se tá incubando, foi } \\
\text { fechado e eu retomo a ideia, né! As } \\
\text { temáticas ás vezes estão paralelas e } \\
\text { circulando, só que há um ano sem } \\
\text { mexer naquela e agora sim ela vem a } \\
\text { tona e acontece.” (atriz) }\end{array}$ \\
\hline - Insight & 5 & $\begin{array}{c}\text { "Surge de pensar muito nos } \\
\text { problemas..." (advogada/defensora } \\
\text { pública) }\end{array}$ \\
\hline - Fluir (Flow) & 1 & $\begin{array}{l}\text { "Acho que a área que eu trabalho é tão } \\
\text { rica, que mesmo quando se está no } \\
\text { momento de lazer, está colecionando } \\
\text { dados..." (relações públicas A) }\end{array}$ \\
\hline \multicolumn{3}{|c|}{ Fatores ambientais favoráveis à criatividade } \\
\hline $\begin{array}{l}\text { - Diversidade } \\
\text { sociocultural }\end{array}$ & 1 & $\begin{array}{c}\text { "Então viajei muito pra fora do Brasil, } \\
\text { viajei muito pelo Brasil..." (atriz) }\end{array}$ \\
\hline
\end{tabular}

Maria Célia Bruno Mundim, Marco Antônio dos Santos, Chaielen Marchiolli Barboza Martinez, Silvana Maria Nader, Solange Muglia Wechsle 
Talento Criativo em Mulheres Brasileiras

Tabela 3. Frequência de respostas das participantes nas categorias e subcategorias da análise de conteúdos relacionados às barreiras e desafios.

\begin{tabular}{|c|c|c|}
\hline \multicolumn{3}{|c|}{ Barreiras } \\
\hline - Familiar & 2 & $\begin{array}{l}\text { "Meu marido não me apoiou..." } \\
\text { (empresária) }\end{array}$ \\
\hline - Profissional & 2 & $\begin{array}{l}\text { "Na defensoria o excesso de trabalho! } \\
\text { Isso prejudica a qualidade do trabalho." } \\
\text { (advogada/defensora pública) }\end{array}$ \\
\hline - Social/cultural & 2 & $\begin{array}{c}\text { "O fato de ser mulher, tem que provar } \\
\text { sempre..." (jornalista) }\end{array}$ \\
\hline \multicolumn{3}{|c|}{ Administração vida pessoal com profissional } \\
\hline - Suporte familiar & 4 & $\begin{array}{l}\text { "Toda a minha família na época foi } \\
\text { contra, disseram não, hoje eles me } \\
\text { apóiam em tudo." (empresária) }\end{array}$ \\
\hline \multicolumn{3}{|c|}{ Desafio(s) atual(is) } \\
\hline - Profissional & 3 & $\begin{array}{l}\text { "Estou em uma fase de transição. } \\
\text { Deixando de ser defensora pública para } \\
\text { buscar ser vereadora. Gostaria de } \\
\text { ampliar a escala do que faço na } \\
\text { defensoria pública, ajudar as pessoas." } \\
\text { (advogada/defensora pública) }\end{array}$ \\
\hline $\begin{array}{l}\text { - Profissional e } \\
\text { pessoal }\end{array}$ & 3 & $\begin{array}{c}\text { "É como se eu tivesse vários braços... } \\
\text { Então eu tô procurando equilibrar } \\
\text { vários pratos... seja no pessoal e na } \\
\text { família, seja na escrita, na academia, } \\
\text { seja enquanto atriz..." (atriz) }\end{array}$ \\
\hline \multicolumn{3}{|c|}{ Interesse pela área de atuação } \\
\hline$-\operatorname{Sim}$ & 4 & $\begin{array}{c}\text { "Eu tenho um jovem profissional que } \\
\text { eu admiro muito, o qual me nomeou } \\
\text { como mentora dele..." (relações } \\
\text { públicas A) }\end{array}$ \\
\hline \multicolumn{3}{|c|}{ Diferença de gênero } \\
\hline - Presença & 4 & $\begin{array}{l}\text { "Os homens são mais objetivos, as } \\
\text { mulheres mais sentimentais..." } \\
\text { (advogada/defensora pública) }\end{array}$ \\
\hline - Ausência & 2 & $\begin{array}{c}\text { "Não. Acho que a nossa área inclusive é } \\
\text { muito da igualdade de gêneros." } \\
\text { (relações públicas A) }\end{array}$ \\
\hline
\end{tabular}

Maria Célia Bruno Mundim, Marco Antônio dos Santos, Chaielen Marchiolli Barboza Martinez, Silvana Maria Nader, Solange Muglia Wechsle 


\section{Discussão}

O objetivo deste estudo foi observar os fatores ambientais e psicológicos que favorecem o talento criativo do gênero feminino por meio de entrevistas com mulheres reconhecidas socialmente como talentosas criativas em diferentes áreas de atuação. As categorias da Análise do Conteúdo foram feitas de acordo com as respostas das participantes.

$\mathrm{Na}$ categoria, brincadeiras na infância, as participantes mostraram atração tanto por brinquedos tradicionais femininos relacionados com bonecas e de casinha quanto por brincadeiras de rua (jogos com bolinha de gude e taco). É comum durante a infância feminina a oferta e o estímulo de brinquedos que imitam as tarefas domésticas, entretanto a criança potencialmente criativa apresenta indicadores comportamentais, como por exemplo, a independência de pensamento e a autonomia, que repercutirão nas brincadeiras, fazendo com que não reproduzam nenhuma prática sexista (PIIRTO, 2004; RUNCO, 2006). Os pais também são importantes para incentivar o desenvolvimento criativo da criança (ALENCAR \& FLEITH, 2003), ao aumentar sua capacidade cognitiva e de socialização, assim como na reprodução dos valores culturais (DELOU, 2007; REICHENBERG \& LANDAU, 2009; SHAVININA, 2013).

Quanto aos comportamentos na adolescência, uma pequena quantidade das participantes revelou ter tido atitude de rebeldia ou de transgressão que são próprios desse período de desenvolvimento. Também em estudo de Nakano e Castro (2013) foi averiguada a relação entre traços de temperamento de extroversão e intuição ao desempenho criativo de pré-adolescentes e adolescentes.

Quanto ao interesse pela área de atuação, a maioria das mulheres revelaram a inclinação ao acaso pela profissão durante a adolescência. Assim sendo, durante essa fase elas já viam sentido de uma carreira, sob a influência ou não de alguma pessoa significativa para elas. Consequentemente a mentoria (na categoria mentoria) mostrou-se presente na fala das mulheres por meio de algum parente próximo, professor ou chefe de trabalho. $O$ que fica demonstrado nos depoimentos ao afirmar a forte influência do pai tentando inclusive copiá-lo, ao chefe por acreditar na profissão e ao reiterar a importância do professor de teatro em sua vida. Também as participantes demonstraram preocupação com a mentoria de jovens que identificaram como talentosos em suas áreas de atuação (categoria identificação de jovens talentosos na área). De acordo com Keinänen e Gardner (2006) e Torrance (1983) o mentor exerce função fundamental para a realização criativa por prover aprendizagem e suporte na carreira profissional da pessoa. Desse modo, o ambiente escolar pode ser um espaço de estímulo para a mentoria do pensamento e do comportamento criativo dos alunos (WECHSLER \& SOUZA, 2011).

No que refere a categoria características pessoais cognitivas, a flexibilidade sobressaiu, seja para as participantes perceberem algum problema de modo diferente ou para tomarem uma decisão diante de uma variedade de possíveis soluções. A flexibilidade tem papel relevante para a pessoa criativa por proporcionar a abertura às novas ideias e às mudanças (SMITH \& AMNER, 
1997).

Já na categoria, características pessoais de personalidade, a abertura ao novo, a atração pela complexidade, a persistência e o inconformismo foram destacados. Estes resultados condizem com as características das pessoas criativas descritas na literatura por Guilford (1967), Starko (2010), Torrance (1995) e Wechsler (2006). Também em estudo com pessoas talentosas criativas brasileiras foram verificadas semelhanças em relação às suas características de personalidade e ao seu estilo de pensar (WECHSLER, VENDRAMINI \& OAKLAND, 2012).

$\mathrm{Na}$ categoria motivação, a motivação intrínseca foi evidenciada pelas mulheres seja como uma necessidade interna ou como uma missão criativa/paixão pelo que faz. A motivação intrínseca está relacionada à dedicação e ao prazer do indivíduo ao executar atividade específica, independente de reforços ambientais (AMABILE, 1996).

Quanto ao processo criativo, o insight, a incubação e o flow foram manifestados pelas mulheres. A incubação tem papel relevante para 0 aparecimento de ideias novas e descobertas durante o processo criativo (SIO \& RUDOWICZ, 2007), pois ao longo daquela, podem surgir maior número de ideias originais por meio do insight, serendipidade ou analogias (PATRICK, 1986). É nesse momento que aparece o estágio do flow, ou seja, a necessidade demonstrada pela pessoa em trabalhar pelo prazer proporcionado com o trabalho por um grande período de tempo, é observado no indivíduo criativo segundo Csikszentmihalyi (1997).

A importância dos fatores ambientais favoráveis à criatividade foi ressaltada apenas pela participante das Artes Cênicas por meio da diversidade cultural, ou seja, viagens nacionais e internacionais. $\mathrm{O}$ ambiente junto a personalidade, a percepção e a habilidade pessoal são determinantes para a produção do talento criativo feminino (REIS, 2005). De modo semelhante Wechsler (2008) refere que o potencial criativo está relacionado à interação entre os processos cognitivos, as características de personalidade e elementos ambientais.

Várias barreiras foram relatadas, tais como o excesso de trabalho, a falta de apoio por parte do esposo e a dificuldade enfrentada no ambiente de trabalho pelo fato de ser mulher. Para Lubart (2007) a cultura pode intervir sob a criatividade de um indivíduo, estimulando ou inibindo sua expressão criativa. Especificamente no que refere ao gênero feminino, Morais (2001) menciona que vários fatores sociais parecem determinar a proporção de sua produção criativa. Além disso, os estereótipos femininos produzem expectativas e preconceitos para a mulher no ambiente de trabalho (ENGEN, LEEDEN \& WILLEMSEN, 2001).

Sobre a administração da vida pessoal com a profissional a maioria das participantes enfatizou a importância do apoio familiar. A mulher ainda é constrangida pelo modo distinto ao qual é tratada em comparação ao homem no mercado de trabalho, impactando em sua vida particular como na profissão (KREIN \& CASTRO, 2015). Em estudo com pesquisadoras de destaque de diferentes áreas foi verificado dificuldades que elas enfrentavam para conciliar a vida profissional com a pessoal, o estereótipo de gênero no decorrer da carreira, além das circunstâncias do trabalho desfavoráveis (PRADO \& 


\section{FLEITH, 2012).}

Sobre os desafios atuais as mulheres citaram aqueles relacionados a vida pessoal e sobretudo a profissão. $\mathrm{O}$ que não vem totalmente de encontro ao que é visto na literatura. A distinção experimentada pela mulher em determinadas áreas profissionais pode fazer com que ela prefira diversificar seus esforços criativos, em oposição a devoção ao seu trabalho (REIS, 2002a). Consequentemente, ela tende a apresentar um nível baixo de valorização de suas aptidões, menosprezando suas habilidades (GARCÍA COLMENARES, 1997).

Quanto às diferenças de gênero, ou seja, a percepção sobre a distinção entre homens e mulheres que trabalham ou trabalharão em sua área, a maioria das participantes reconheceram a sua existência a favor do sexo masculino. Autores como Lombardi (2004), Hackley e Kover (2007) e Nogueira (2011) alegam que diversas áreas, como a de exatas e as científicas ainda privilegiam o sexo masculino.

Portanto, o entendimento dos aspectos ambientais e de personalidade foram essenciais para elucidar o desenvolvimento da excelência criativa das participantes. As mulheres demonstraram brincadeiras pouco estereotipadas durante a infância, bem como comportamentos de rebeldia típicos da adolescência. A vocação profissional ocorreu na juventude por meio de um modelo de um mentor no ambiente familiar, escolar ou de trabalho.

O desenvolvimento da carreira das participantes, por sua vez, revelou a necessidade do suporte familiar, além do predomínio de características pessoais, tais como inconformismo, abertura ao novo, atração pela complexidade, persistência e flexibilidade. Estas características somadas à motivação intrínseca possibilitam que as mulheres enfrentem as barreiras no ambiente de trabalho.

A limitação deste estudo foi a quantidade reduzida de participantes. Por se tratar de um estudo exploratório acerca de um tema pouco pesquisado, indicam-se amostras de maior tamanho para que resultados mais fidedignos sob o enfoque estatístico possam ser encontrados. Todavia, neste estudo podem ser ressaltados os fatores que tem sido demonstrados na literatura sobre a excelência criativa feminina, principalmente os aspectos psicológicos e as condições ambientais. Aspectos estes que podem suscitar considerações sobre ações que estimulem as lideranças femininas com potencial criativo a ampliarem seu desenvolvimento e posicionamento junto a sociedade.

\section{Referências}

ALENCAR, Eunice Maria Soriano; FLEITH, Denise de Souza. Criatividade: múltiplas perspectivas. Brasília: EdUnB, 2003.

ALENCAR, Eunice Maria Soriano. Criatividade pessoal: fatores facilitadores e inibidores segundo estudantes de engenharia. Magis, Revista Internacional de Investigación en Educación, v.1, p. 113 - 126, 2008.

ALENCAR, Eunice Maria Soriano; VIRGOLIM, Angela Magda Rodrigues. 
Dificuldades emocionais e sociais do superdotado. In: ALENCAR, Eunice Maria Soriano (Org.). Criatividade e educação dos superdotados. Petrópolis: Vozes, 2001, p. $174-205$.

ALMEIDA, Leandro da Silva; WECHSLER, Solange Muglia. Excelência profissional: a convergência necessária de variáveis psicológicas. Estudos de Psicologia-Campinas, v. 32, n. 4, p. 767 - 775, 2015.

AMABILE, Teresa. Creativity in Context. Oxford: Westview Press, 1996.

BARDIN, Laurence. Análise de conteúdo. Lisboa: Edições 70, 2011.

CAMPOS, Rafaella Cristina et al. Gênero e Empoderamento: Um Estudo sobre Mulheres Gerentes nas Universidades. Revista Latino-Americana de Geografia e Gênero, v. 8, n. 2, p. 97 - 115, 2018.

CORRÊA, Mariza. Do feminismo aos estudos de gênero no Brasil: um exemplo pessoal. Cadernos Pagu, v. 16, p. 13 - 30, 2001.

CSIKSZENTMIHALYI, Mihaly. Creativity: flow and the psychology of discovery and invention. New York: Harper Collins, 1997.

CSIKSZENTMIHALYI, Mihaly. Implications of a systems perspective for the study of creativity. In: STERBERG, Robert Sternberg (Org.), Handbook of creativity. Cambridge, USA: Cambridge University Press, 2005, p. 313 - 335.

DELOU, Cristina Maria Carvalho. O papel da família no desenvolvimento de altas habilidades e talentos. In: FLEITH, Denise de Souza (Org.). A construção de práticas educacionais para alunos com altas habilidades/superdotação. Orientação a professores. Brasília: MEC/SEESP, 2007, p. $49-60$.

ENGEN, Marloes Van; LEEDEN, Rien Van Der; WILLEMSEN, Tineke. Gender, context and leadership styles: a field study. Journal of Occupational and Organizational Psychology, v. 74, n. 5, p. 581 - 598, 2001.

GARCIA COLMENARES, Carmen. Género y superdotación: las mujeres superdotadas. Superdotados: problemática e intervención. Valladolid: Universidad deValladolid, 1997.

GUENTHER, Zenita Cunha. Desenvolver capacidades e talentos: um conceito de inclusão. Petrópolis: Vozes, 2000.

GUENTHER, Zenita Cunha; RONDINI, Carina Alexandra. Capacidade, dotação, talento, habilidades: uma sondagem da conceituação pelo ideário dos educadores. Educação em Revista, v. 28, n. 1, p. 237 - 266, 2012. 
GUILFORD, Joy Paul. The nature of human intelligence. New York: McGraw-Hill Book Company, 1967.

HACKLEY, Chris; KOVER, Arthur. The trouble with creatives: negotiating creative identity in advertising agencies. International Journal of Advertising, v. 26, n. 1, p. $63-78,2007$.

HILL, Catherine; CORBETT, Christianne; ST. ROSE, Andresse. Why so few? Women in Science, technology, engeneering and mathematics. Washington, DC: American Association of University Women, 2010.

INSTITUTO BRASILEIRO DE GEOGRAFIA E ESTATÍSTICA. Mulheres no mercado de trabalho. Disponível em $<$ http://www.ipea.gov.br/sites/000/2/livros/2009/Livro_RetratoDesigual.pdf $>$ Acesso em 20 de novembro de 2016.

KEINÄNEN, Mia; GARDNER, Howard. Vertical and horizontal mentoring for creativity. In: STERNBERG, Robert; GRIGORENKO, Elena; SINGER, Jerome (Orgs.), Creativity from potential to realization. Washington: American Psychological Association, 2006, p. 169 - 194.

KREIN, José Dari; CASTRO, Bárbara. As formas flexíveis de contratação e a divisão sexual do trabalho. Disponível em <http://www.cesit.net.br/wpcontent/uploads/2016/06/TD_FES_Dari.pdf $>$ Acesso em 04 de fevereiro de 2017.

LADEGAARD, Hans. Doing power' at work: Responding to male and female management styles in a global business corporation. Journal of Pragmatics, v. 43, p. 4 - 19, 2011.

LANDAU, Erika. A coragem de ser superdotado. São Paulo: Arte \& Ciência, 2002.

LOMBARDI, Maria Rosa. Perseverança e resistência: a engenharia como profissão feminina. 2004. Tese (Doutorado em Educação), Faculdade de Educação da UNICAMP, Campinas.

LUBART, Todd. Psicologia da criatividade. Porto Alegre: Artmed, 2007.

MACHADO, Lia Zanotta. Gênero, um novo paradigma? Cadernos Pagu, v. 11, p. 107 - 125, 1998.

MADALOZZO, Regina; MARTINS, Sérgio Ricardo; SHIRATORI, Ludmila. Participação no mercado de trabalho e no trabalho doméstico: homens e mulheres têm condições iguais? Estudos Feministas, v. 18, n. 2, p. 547 - 566, 2010 .

MARTINSEN, Øyvind Lund. The creative personality: A synthesis and Maria Célia Bruno Mundim, Marco Antônio dos Santos, Chaielen Marchiolli Barboza Martinez, Silvana Maria Nader, Solange Muglia Wechsle 
development of the creative person profile. Creativity Research Journal, v. 23, n. 3, p. 185 - 202, 2011.

MORAIS, Maria de Fátma. Definição e avaliação da criatividade. Braga: Universidade do Minho, 2001.

MORAIS, Maria de Fátma. Creativity: Challenges to a key-concept for the twenty first century. In: ANTONIETTI, Alessandro; COLOMBO, Bárbara e MEMMERT, Daniel (Orgs.), Psychology of creativity: advances in theory, research and application. New York: Nova Publishers, 2013, p. 3 - 19.

MUNDIM, Maria Célia Bruno e WECHSLER, Solange Muglia. Excelência criativa em mulheres brasileiras. Estudos e Pesquisas em Psicologia, v. 15, n. 3, p. $797-813,2015$.

MUNDIM, Maria Célia Bruno; MORAIS, Maria de Fátma; WECHSLER, Solange Muglia. Mulheres com excelência criativa em Portugal. Psicologia, educação e cultura, v. 9, n. 2, p. 188 - 204, 2015.

NAKANO, Tatiana de Cássio. Sugestões práticas e estratégias para o desenvolvimento e treinamento de características associadas à criatividade. In: MORAIS, Maria de Fátima; MIRANDA, Lúcia; WECHSLER, Solange Muglia. Criatividade: aplicações práticas em contextos internacionais. São Paulo: Vetor, 2015, p. $229-256$.

NAKANO, Tatiana de Cássio; CASTRO, Lívia Rech. Relação entre criatividade e traços temperamentais em estudantes do ensino fundamental. Psico USF, v. 18, n. 2, p. 249 - 261, 2013.

NOGUEIRA, Pablo. A ciência das mulheres. Revista Unesp Ciência, v. 17, p. $18-49,2011$.

OBERHAUSEROBERHAUSER, Ann; RUBINOFF, Donna; BRES, Karen; MAINS, Susan; POPE, Cindy. Geographic Perspective on Woman. In: GAILE, Gary; WILLMOTT, Cort. (Orgs). Geography in America at the Dawn of the 21st Century. Oxford: Oxford University Press, 2003, p. 736 - 758.

OECD. O que está por trás da desigualdade de gênero na educação? Disponível em <https://www.oecd.org/pisa/pisaproducts/pisainfocus/PIF$49 \% 20$ (por).pdf $>$ Acesso em 12 de dezembro de 2016.

NOLNA, Sylvie Kwedi; MEKONGO, Pierrete Essama; LEKE, Rose. Mentoring for early-career women in health research: the HIGHER Women Consortium approach. Global Health, Epidemiology and Genomics, v. 2, p. $1-4,2017$.

PATRICK, Andrew. The role of ability in creative 'incubation. Personality and Individual Differences, v. 7, n.2, p. 169 - 174, 1986. 
PEARCE, Lucy. The Rainbow Way: Cultivating Creativity in the Midst of Motherhood, Alresford: John Hunt Publishing, 2013.

PÉREZ, Susana Graciela Barrera; FREITAS, Soraia Napoleão. Do pecado de ser mulher ao medo de ser mulher com altas habilidades/superdotação. In: FLEITH, Denise de Souza e ALENCAR. Eunice Maria Soriano de (Orgs.) Superdotados - Trajetórias de Desenvolvimento e Realizações. Curitiba: Juruá, 2013, p. 55 - 73.

PEUS, Claudia; BRAUN, Susanne; KNIPFER, Kristin. On becoming a leader in Asia and America: Empirical evidence from women managers. The Leadership Quarterly, v. 26, n. 1, p. 55 - 67, 2015.

PIIRTO, Jane. Understanding creativity. Scottsdale: Great Potential, 2004.

PINTO, Céli Regina Jardim. Feminism, history and power. Revista de Sociologia e Política, v. 18, n. 36, p. 15 - 23, 2010.

PRADO, Renata Muniz; FLEITH, Denise de Souza. Pesquisadoras brasileiras: conciliando talento, ciência e família. Arquivos Brasileiros de Psicologia, v. 64, n. 2, p. 19 - 34, 2012.

REICHENBERG, Abraham; LANDAU, Erika. Families of gifted children. In: SHAVININA, Larisa (Org.), International handbook on giftedness. Amsterdam: Springer Science, 2009, p. 873 - 883.

REIS, Sally. Social and Emotional Issues Faced by Gifted Girls in Elementary and Secondary School. The SENG Newsletter, v. 2, n. 3, p. 1 - 5, 2002a.

REIS, Sally. Internal barriers, personal issues, and decisions faced by gifted and talented females. Gifted Child Today, v. 25, n. 1, p. 1 - 21, 2002b.

REIS, Sally. Feminist perspective on talent development: A research-based conception of giftedness in women. In: STERNBERG, Robert; DAVIDSON, Janet (Orgs.), Conceptions of giftedness. New York: Cambridge University Press, 2005, p. $217-245$.

RIETZSCHEL, Eric; NIJSTAD, Bernard; STROEBE, Wolfgang. Relative accessibility of domain knowledge and creativity: The effects of knowledge activation on the quantity and originality of generated ideas. Journal of Experimental Social Psychology, v. 43, n. 6, p. 933 - 946, 2007.

RUNCO, Mark. The development of children's creativity. In: SPODEK, Bernard; SARACHO, Olivia (Orgs.), Handbook of research on the education of young children. New York: Routledge, 2006, p. $121-131$.

RUNCO, Mark. Creativity - Theories and Themes: Research, Development 
and Practice. California: Elsevier, 2007.

RUNCO, Mark; JAEGER, Garrett. The standard definition of creativity. Creativity Research Journal, v. 24, n. 1, p. 92 - 96, 2012.

RUNCO, Mark A.; PRITZKER, Steven R. (Orgs.). Encyclopedia of creativity. San Diego: Academic Press, 2011.

SHAVININA, Larisa. The Role of Parents and Teachers in the Development of Scientific Talent: Lessons from Early Childhood and Adolescent Education of Nobel Laureates. Gifted and Talented International, v. 28, n. $1-2$, p. 11 $24,2013$.

SILVA, Sofia de Lourdes Rosas; FERREIRA, Joaquim Armando Gome; FERREIRA, Antonio Gomes. Vivências no ensino superior e perceções de desenvolvimento: dados de um estudo com estudantes do ensino superior politécnico. Revista E-Psi, v. 1, p. 5 - 27, 2014.

SIMONTON, Dean Keith. Creativity: Cognitive, personal, developmental, and social aspects. American psychologist, v. 55, n. 1, p. 151 - 160, 2000.

SMITH, Gudmund; AMNER, Gunilla. Creativity and perception. In: RUNCO, Mark (Org.), The creativity research handbook. Cresskill, NJ: Hampton Press, 1997, p. $147-162$.

SIO, Ut Na e RUDOWICZ, Elisabeth. The role of an incubation period in creative problem solving. Creativity Research Journal, v. 19, n. 2 - 3, 307 318, 2007.

STARKO, Alane Jordan. Creativity in the classroom - schools of curious delight. New York: Routledge, 2010.

TOH, Soo Min.; LEONARDELLI, Geoffrey. Cultural constraints on the emergence of women as leaders. Journal of World Business, v. 47, n. 4, p. $604-611,2012$.

TORRANCE, Ellis Paul. Role of mentors in creative achievement. Creative Child \& Adult Quarterly, v. 8, n. 1, p. 8 - 15, 1983.

TORRANCE, Ellis Paul. Why fly? A philosophy of creativity. New Jersey: Ablex Publishing Corporation, 1995.

TORRANCE, Ellis Paul; GOFFF, Kathy e SATTERFIELD, Neil. Multicultural mentoring of the gifted and talented. Waco, TX: Prufrock Press, 1998.

WALTON, Andre; KEMMELMEIER, Markus. Creativity in its social context:

The interplay of organizational norms, situational threat, and 
gender. Creativity Research Journal, v. 24, n. 2 - 3, p. 208 - 219, 2012.

WECHSLER, Solange Muglia. Validity of the Torrance Tests of Creative Thinking to the Brazilian culture. Creativity research journal, v. 18, n. 1, p. $15-25,2006$.

WECHSLER, Solange Muglia. Criatividade: descobrindo e encorajando. São Paulo: Editora Psy, 2008.

WECHSLER, Solange Muglia; GUERREIRO, Maria da Conceição. Fatores biográficos influenciantes na criatividade da mulher brasileira. Educação e Realidade, v. 11, n. 2, p. 81 - 86, 1986.

WECHSLER, Solange Muglia; SOUZA, Vera Lúcia Trevisan. Criatividade e aprendizagem: caminhos e descobertas em perspectiva internacional. São Paulo: Loyola, 2011.

WECHSLER, Solange Muglia; VENDRAMINI, Claudette Maria Medeiros; OAKLAND, Thomas. Thinking and creative styles: A validity study. Creativity Research Journal, v. 24, n. 2 - 3, p. 235 - 242, 2012.

WECHSLER, Solange Muglia, $\underline{\text { ROMO, Manuela; }}$ MORAIS, Maria de Fátima (2013). (Trabalho não publicado).

WHITTEN, Donna. Mentoring and Work Engagement for Female Accounting, Faculty Members in Higher Education. Mentoring \& Tutoring: Partnership in Learning, v. 24, n. 5, p. 365 - 382, 2017. 